\title{
QUEUE BALANCING OF LOAD AND EXPEDITION SERVICE IN A CEMENT INDUSTRY IN BRAZIL
}

\author{
David Custódio de Sena \\ Federal University of Semiarid, Brazil \\ E-mail: sena@ufersa.edu.br \\ Eva Falcão Soares \\ Federal University of Semiarid, Brazil \\ E-mail: eva_falcao@yahoo.com.br \\ Izabelle Virginia Lopes de Paiva \\ Federal University of Semiarid, Brazil \\ E-mail: izabelle.lopes@yahoo.com.br \\ Breno Barros Telles do Carmo \\ Federal University of Semiarid, Brazil \\ E-mail: brenobarros@ufersa.edu.br
}

Submission: 08/07/2013

Accept: 24/07/2013

\begin{abstract}
The load and weight process in a cement industry is one of logistic step that shows the biggest time of occurrence, increasing the queues. This study aims to do scenarios to solve this queue problem. This way, it pretends to find an better resources distribution.
\end{abstract}

Keywords: Simulation, Cement, Queue. 
DOI: 10.14807/ijmp.v4i2.108

\section{INTRODUCTION}

The load and weight process in a cement industry is ones of logistic process that generate the biggest time of occurrence, increasing the queues and increasing the lead time. Another concern is related to costs of production and productive capacity. According to (WIENDAHL, 1995), shorts lead times facilitate compliance with the due dates. The loading full and probable increases the occupation of productive resources and reduces the cost, given same goal factory.

In the cement industry, the transportation of raw materials and finished products is done by cargo vehicles, with capacity for large batches of cement either bagged or bulk cement, reflecting thus in occupation of active load (and equipment to load in bulks forklifts) for long periods of time, increasing the queues. One solution to the above problem would be to acquire more charging equipment; moreover, the costs to purchase, install and put into use this new equipment will increase.

Thus, the company faces a trade-off between investing in new resources or not, with no knowledge if the modification may bring significant benefits to the process and what these benefits would be. A useful technique in solving problems of this nature, where there is variation and choices involved in the process, is the use of computer simulation. Through simulation, you can test and analyze different settings for resources and their potential impacts in productive system. Because this technique is done virtually, no need physical intervention is required in the real system, thus demanding low investment.

The objective of this work is to simulate alternatives to solve the problem of queues in the activities of weighing and loading cargo vehicles in a cement factory in the interior of the Brazilian state Rio Grande do Norte. The study considers the loads carried by trucks and bulk, looking for an alternative that reduces the average waiting time of customers per charge and the consequences of alternative resource use and costs for the company.

\section{SIMULATION}

There are a lot of definitions of simulation. Some are general and include both the computational models as the physical models, the definition of Gordon (1978) that says that systems simulation is the technique of solving problems by observing the performance of a dynamic system's model over time. Shannon (1975) also 
provides a global view to say that simulation is the process of developing a real system's model that conducts experiments in this model, in order to understand the behavior of the system and / or evaluating various strategies (with is limited by a criterion or a set of criteria) for system operation.

Naylor et al. (1971) offers a definition based on computers for experimentations in which simulation is a numerical technique for conducting experiments on a digital computer, involving some types of logic models that describe the behavior of an economic system or business (or a partial aspect of one) over long time intervals.

According Doukidis (1987), the primary function of a simulation model is to examine how the system behaves over a period of time. To achieve this goal, the model should provide facilities to represent the current state of the system, and various pre-conditions which, if met, will result in a future state.

\section{METHODOLOGY}

The methodology adopted for the development of this study follows the stages of the simulation process shown in Figure 1.

This paper is a case study of a descriptive nature, also involves the use of standardized techniques of data collection, in which we used systematic observation.

The study was started with the company's choice. It was later searched a better understanding of the production process, in order to define, clearly and objectively, the problem to be solved, and the study plan. At this stage, each relevant information was analyzed in order to identify the problem at level of goals, as well as the constraints and complexities, since it is not possible solve a problem without knowing it deeply. The first step is to clearly define the related goals to the problem to be solved. At this stage the process was modeled with the aid of two tools Flowchart and IDEF-SIM.

The second stage of the study is to perform preliminary planning and observation of data collection in order to obtain a faithful representation of the problem. These data relate to the arrival intervals of clients, here called 'customers entities', and the length of stay of the system, i.e. the duration of attendance.

Using these data entry was performed followed by a statistical analysis (with 
input analyzer $($ )), whose main objective is to measure the theoretical distribution curve of probabilities that best reproduces the behavior of each data set. After statistical treatment done this, the next step is to develop a computer program for the proposed scenario using the software Simpy. Thus, it appears to ensure that all specifications were met and implemented, and finally, the model must be validated and executed.

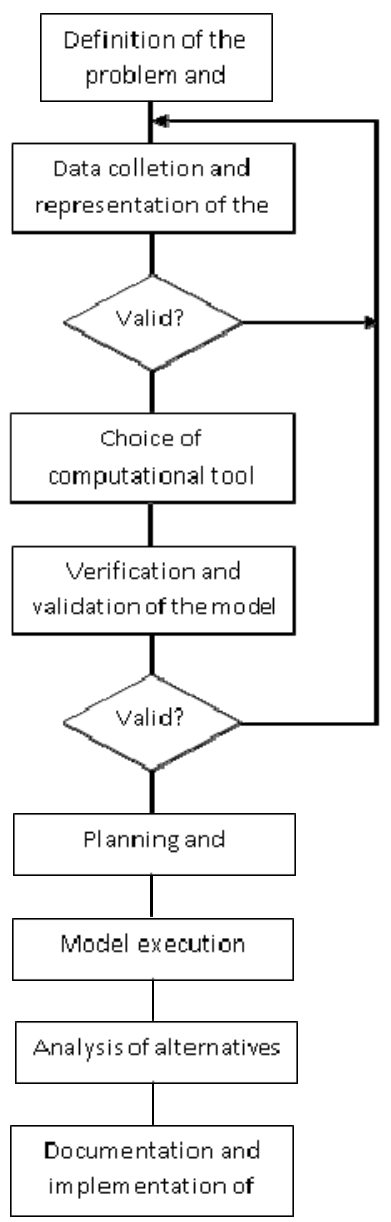

Figure 1: Stages of Simulation Process

\section{PROBLEM DEFINITION}

The cargo vehicles arrive at the factory and wait in a queue to be served. After the balance becomes available, then the cargo vehicle starts to be served in order to identify, collect license plate number, to collect the name of the driver, to collect the name of the company, to collect the name of the application, the day of tare of the truck, and then receive authorization for loading. This done, it follows to the supply, which can be bagged or in bulk.

The bagged cement is stacked on pallets, ready to be loaded. The operator carries out routine procedures such as the preparation and cleaning of the vehicle 
body. The forklift then starts placing the pallets on the car, in which depending on the capacity, accommodates up to 7 pallets with 40 bags of $50 \mathrm{~kg}$ each $(14000 \mathrm{~kg})$. In normal operating conditions, this procedure takes around 20 to 30 minutes. It is worth mentioning that there are two forklifts to carry the load of vehicles therethus waiting for customers at certain hours of the day. The figure below illustrates what has been described previously:

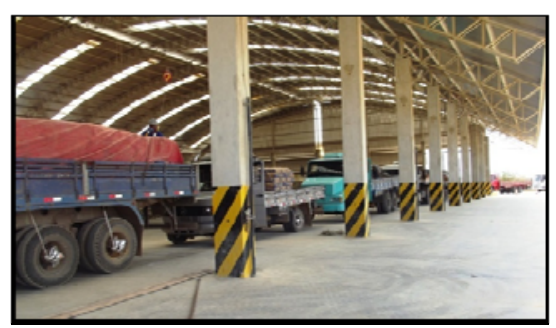

Figure 2: Cargo vehicles waiting loading

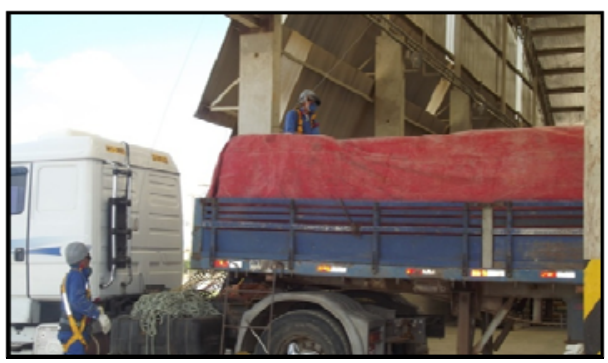

Figure 3: Loading complete

The other form for the loading of vehicles is the in bulk supply, where the empty vehicles are performing the same procedure weight (tare) defined above and are directed to one of two equipment to load in bulks loading. As the loading of bagged cement, the duration of this procedure is around 30 minutes per truck. After loading, the vehicle returns to the entrance where your new weight is determined, now with the cargo.

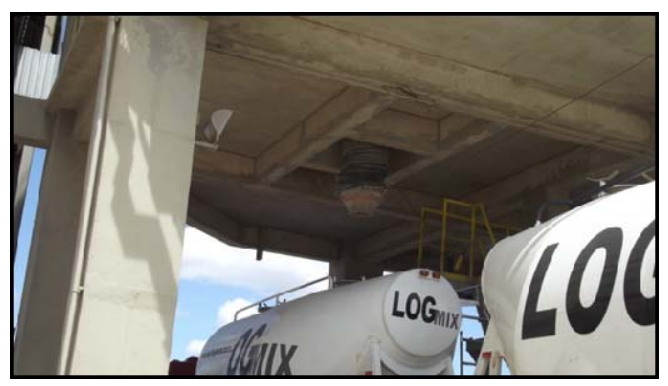

Figure 4: Supply in bulk 


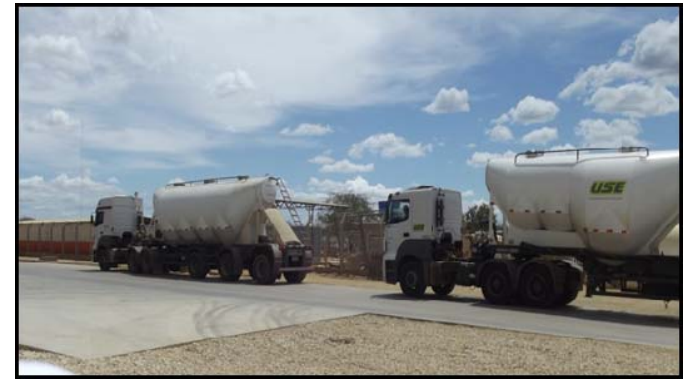

Figure 5: Queue of vehicles waiting supply

\section{MODELING OF THE SERVICE PROCESS}

The procedures described in the previous section consume around 30 minutes. This study is considering the full-time load as the sum of the times: 1) The vehicle's access to the equipment to load in bulk / industry; 2) Preparation of the equipment to load in bulk and loading; 3) Losing time because malfunction during fueling; 4) Set manual canvas - for expedition bagged; 5) Access to the weighing pan, final weighing and calculation of tax. Then, using modeling tools (Flowchart and IDEF - SIM), it will demonstrate the behavior of vehicle from the moment of arrival in industrial plant until its release.

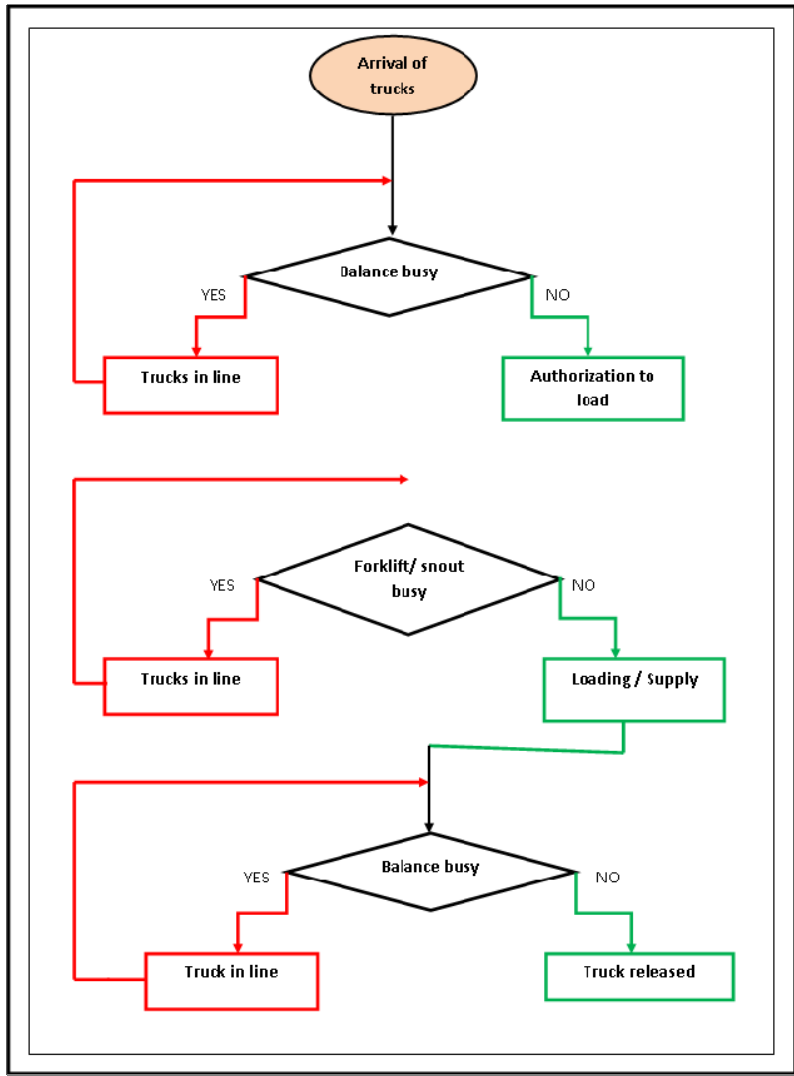

Figure 6: Modelling the service process - Flowchart 


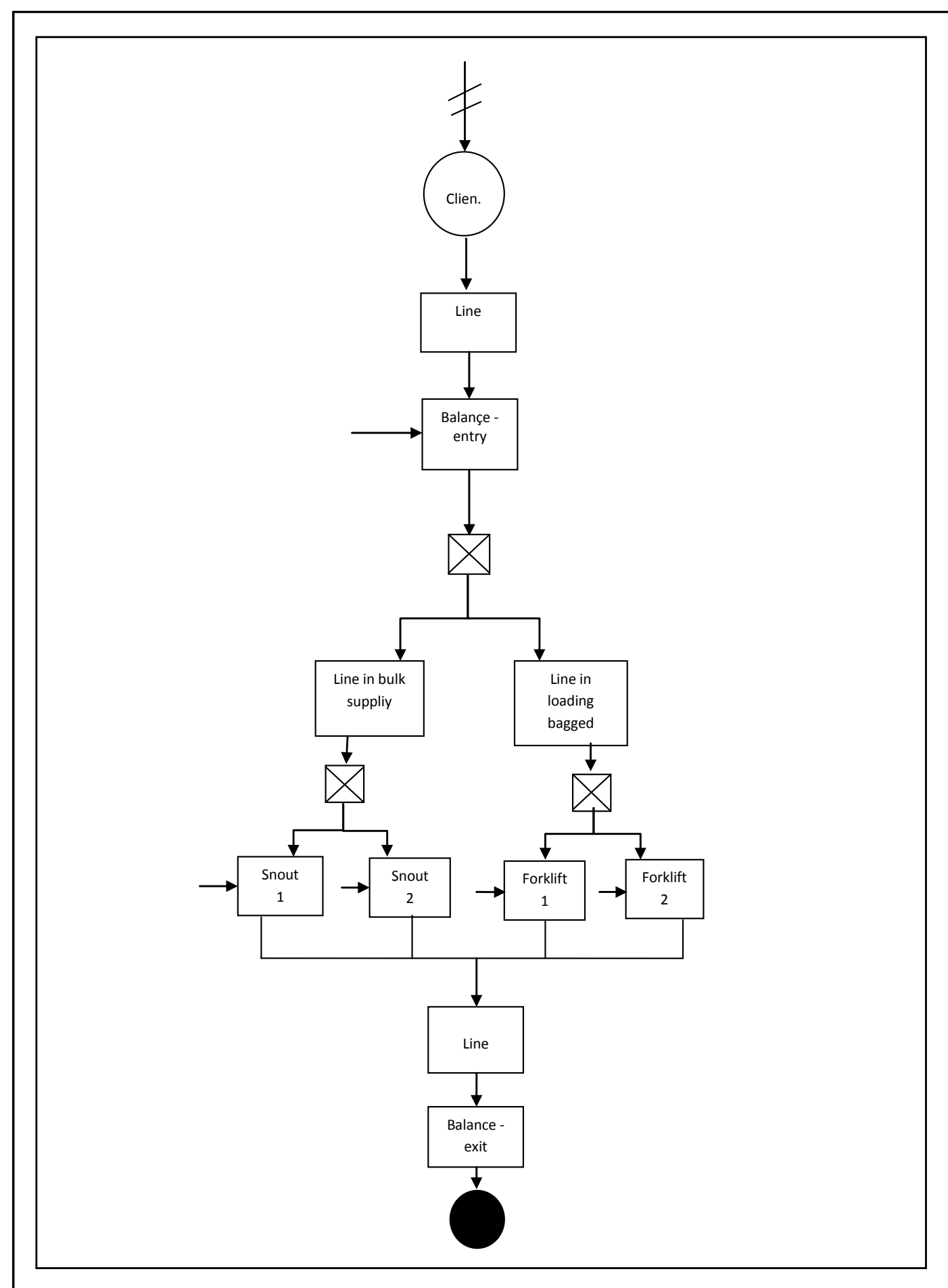

Figure 7: Modeling the processo of attended - IDEF-SIM

\subsection{The problem}

The arrival rate of vehicles in the industrial plant is more intense between $10 \mathrm{~h} 00$ and $17 \mathrm{~h} 00$. In the factory there are two weighing - One for vehicles that will supply and another for vehicles that will make loading. It was observed that the intervals between arrivals of vehicles are greater than the processing time, characterizing the emergence of queues in both loaging (bagged or in bulk). A 
DOI: 10.14807/ijmp.v4i2.108

service process for cargo vehicles consists in a loading order that comes to an operation waits its turn in the queue, it is processed and finally dispatched. The order of service is subject to priorities exchange and interruptions for maintenance or lack of materials. (SELITTO, BOCHARDT, PEREIRA, 2009). It is noticeable that vehicles face more than one queue, with the highest waiting time is the first, in weighing scale. Á priori, this happens because of the reduced number of attendants ( 3 employees) to handle various demands and still receiving raw material. With background, there is the limitation of resources ( 2 equipment to load in bulk and 2 forklifts) that contributes to increasing the waiting time.

In general, the specific objective of this study is to identify alternatives, through computer simulation, to decrease the waiting time. The parameters used for decision making were based on the traditional characteristics of the queue according to Table 1 , with real data.

Table 1: Queue characteristics

\begin{tabular}{|c|c|}
\hline Arrival interval & 11,31 minutes \\
\hline Rate of arrival & 0,09 vehicles per minute \\
\hline $\begin{array}{c}\text { Average service time weighing scale - } \\
\text { loading - weighing scale }\end{array}$ & 45,62 minutes \\
\hline Service rate & 0,02 vehicles per minute \\
\hline $\begin{array}{c}\text { Average waiting time weighing scale - } \\
\text { loading - weighing scale }\end{array}$ & 47,88 minutes \\
\hline
\end{tabular}

\subsection{Analysis of output data}

The simulation was performed with 3 different scenarios to achieve the research objective, which is to find the best alternative to minimize the time customers wait queue in loading operation.

In the first scenario it is considered the acquisition of a weighing scale to work in parallel with that already exists in the input stream of vehicles. This would divide the existing single queue at this stage, also requiring the hiring of at least one attendant to supply the deficiency. Therefore, it was projected the proposed scenario 1 , which it was obtained the results shown in Table 2. 
INDEPENDENT JOURNAL OF MANAGEMENT \& PRODUCTION (IJM\&P)

http://www.ijmp.jor.br

V. 4, n. 2, July - September 2013.

ISSN: 2236-269X

DOI: 10.14807/ijmp.v4i2.108

Table 2: Scenario 1 simulated

\begin{tabular}{|c|c|c|c|}
\hline \multicolumn{4}{|c|}{ Scenario 1 } \\
\hline Characteristics & $\begin{array}{c}\text { Average time in } \\
\text { queue }\end{array}$ & $\begin{array}{c}\text { Simulated dverage } \\
\text { time in queue }\end{array}$ & $\begin{array}{c}\text { Reduction of waiting time } \\
\text { (\%) }\end{array}$ \\
\hline $\begin{array}{c}\text { weighing scale } \\
\text { (entrance) } \\
+ \\
\begin{array}{c}\text { Hiring an } \\
\text { attendant }\end{array}\end{array}$ & 26,45 minutes & $\begin{array}{c}13,69 \\
\text { minutes }\end{array}$ & \\
& & & $48,24 \%$ \\
\hline
\end{tabular}

In a second and third scenario, the change occurred only in loading operations for optimization. It is observed that a major average waiting time occurs in the operations of loading of bags (forklift) and in bulk (Equipment to load in bulk). It was then searched in the second scenario, the reduction for the time in queue by adding a forklift making three resources available for loading bags. This new context requires hiring a new forklift operator. Likewise in the third scenario, a equipment to load in bulk was increased to accelerate the cement supply in bulk, with hiring a new worker handling the equipment to load in bulk. The following tables gather the data obtained from these situations:

Table 3: Scenario 2 simulated

\begin{tabular}{|c|c|c|c|}
\hline \multicolumn{3}{|c|}{ Scenario 2 } \\
\hline Characteristics & $\begin{array}{c}\text { Average time in } \\
\text { queue }\end{array}$ & $\begin{array}{c}\text { Simulated dverage } \\
\text { time in queue }\end{array}$ & $\begin{array}{c}\text { Reduction of waiting time } \\
\text { (\%) }\end{array}$ \\
\hline $\begin{array}{c}\text { Forklift } \\
+ \\
\begin{array}{c}\text { Hiring an } \\
\text { attendant }\end{array}\end{array}$ & 33,77 minutes & 23,16 minutes & $31,41 \%$ \\
\hline
\end{tabular}

Table 4: Scenario 3 simulated

\begin{tabular}{|c|c|c|c|}
\hline \multicolumn{3}{|c|}{ Scenario 3 } \\
\hline Characteristics & $\begin{array}{c}\text { Average time in } \\
\text { queue }\end{array}$ & $\begin{array}{c}\text { Simulated average } \\
\text { time in queue }\end{array}$ & $\begin{array}{c}\text { Reduction of waiting time } \\
\text { (\%) }\end{array}$ \\
\hline $\begin{array}{c}\text { Equipment to } \\
\text { load in bulk } \\
+ \\
+ \\
\text { Hiring an } \\
\text { attendant }\end{array}$ & 29,41 minutes & 23,18 minutes & $21,18 \%$ \\
\hline
\end{tabular}

The fourth scenario is similar to first on, this one proposed to buy another 
weighing scale. The new resource would work in parallel with the existing one, to minimize the size and the average queue time. The new acquisition, as already shown in the first scenario, requires hiring a new clerk. Considering all other variables unchanged simulation, the results are shown on Table 5.

Table 5: Scenario 4 simulated

\begin{tabular}{|c|c|c|c|}
\hline \multicolumn{3}{|c|}{ Scenario 4 } \\
\hline Characteristics & $\begin{array}{c}\text { Average time in } \\
\text { queue }\end{array}$ & $\begin{array}{c}\text { Simulated average } \\
\text { time in queue }\end{array}$ & $\begin{array}{c}\text { Reduction of waiting time } \\
\text { (\%) }\end{array}$ \\
\hline $\begin{array}{c}\text { weighing scale } \\
+ \\
\begin{array}{c}\text { Hiring an } \\
\text { attendant }\end{array}\end{array}$ & 31,23 minutes & 19,34 minutes & $38,07 \%$ \\
\hline
\end{tabular}

The fifth, and the last, proposed scenario is also called optimal scenario in which includes all the changes suggested above. The average time in queue is considered real is the sum of the times in queue for each step (+ Load Balance-entry - Trunk / + Forklift Scale-out). Obviously, this scenario requires a high initial investment, but in terms of simulation time in queue, it is important get a more holistic view. The table 6 shows the fifth scenario analyzed.

Table 6: Scenario 5 simulated

\begin{tabular}{|c|c|c|c|}
\hline \multicolumn{4}{|c|}{ Scenario 5} \\
\hline Characteristics & $\begin{array}{c}\text { Average time in } \\
\text { queue }\end{array}$ & $\begin{array}{c}\text { Simulated average } \\
\text { time in queue }\end{array}$ & $\begin{array}{l}\text { Reduction of waiting time } \\
(\%)\end{array}$ \\
\hline $\begin{array}{c}2 \text { weighing scale } \\
+ \\
2 \text { attendant } \\
+ \\
1 \text { Equipment to } \\
\text { load in bulk } \\
+ \\
\text { Forklift } \\
+ \\
\text { Operators }\end{array}$ & 47,88 minutes & 8,31 minutes & $82,64 \%$ \\
\hline
\end{tabular}

\section{CONCLUSION}

This paper presented a suggestion for improving the cargo vehicles service at cement industry reducing the time spent of vehicles in logistics operations and cargo dispatch. For this purpose, the program Simpy was used for simulates scenarios more optimized, reducing the waiting time and therefore the queue of vehicles.

As can be observed, the highest times of vehicles queued are the operations 
supply and load. Therefore, it was proposed the acquisition of new physical resources and staffing (scales, trunks, forklifts and operators and attendants) in order to speed up the processing of entities.

Thus, it was shown that the inclusion of new features is reflected by a decrease of at least $21.18 \%$ in waiting time.

\section{REFERENCES}

DOUKIDIS, G. (1987) Ananthology on the homology os simulation with artificial intelligence. Journal of operation Research Society, v. 38, n. 8. Grã-Bretanha.

GORDON, G. (1978) System Simulation, 2nd ed. Englewood Cliffs, New Jersey, Pratice Hall, p. 423.

NAYLOR, T. H.; JOSEPH L.; BALINTFY, D. S.; BURDICK, K. C. (1971) Técnicas de Simulação em Computadores. São Paulo: Editora Vozes em colaboração com a Editora da Universidade de São Paulo.

SELITTO, M. A.; BOCHARDT, M.; PEREIRA, G. M. (2009) Análise de uma operação logística de carregamento e expedição de cimento por simulação computacional. Revista Gestão industrial - UTFPR.

SHANNON, R. E. (1975) Systems simulation: the art and science. Englewood Cliffs: Prentice Hall, Inc. 387p.

WIENDAHL, H. P. (1995) Load-oriented manufacturing control. Berlin: SpringerVerlag. 